\title{
Comparative Efficacy of Experimental Solutions in Occluding Dentin Tubules: Calcium Phosphate Based and Oxalate-Based Solutions
}

Haijing Gu, Xiaoyan Zhou, Junqi Ling, Limin Liu, Ziming Zhao and Jinlong Gao*

The University of Sydney Westmead, Australia (NSW)

*Corresponding author: Jinlong Gao, Institute of Dental Research, Westmead Centre for Oral Health. Westmead, NSW 2153, Australia, Tel: 6198458772; E-mail: jinlong.gao@sydney.edu.au

Received date: February 07, 2017; Accepted date: Feburary 15, 2017; Published date: February 21, 2017

Copyright: ( $2017 \mathrm{Gu} \mathrm{H}$, et al. This is an open-access article distributed under the terms of the Creative Commons Attribution License, which permits unrestricted use, distribution, and reproduction in any medium, provided the original author and source are credited.

\begin{abstract}
To investigate the efficacy in occluding dentin tubules of a modified calcium phosphate based solution supplemented with fluoride and zinc ions (CaP), dentine discs were separately treated with $\mathrm{CaP}$ and certain common desensitizing agents including potassium oxalate solution (OX), modified oxalate solutions supplemented with calcium ions $(O X / C a)$ or phosphate ions $(O X / P)$ for 8 minutes, followed by occluding abilities evaluation with scanning electron microscopy (SEM). CaP showed the highest per cent of sealed dentin tubules and penetrated the most deeply into the tubules, whereas the oxalate modified and unmodified groups showed predominantly open or partially occluded tubules. OX/Ca and OX/P were more efficient in occluding dentin tubules compared with OX. Furthermore, the occluded material obtained with the experimental CaP solutions was more stable (less susceptible to acid dissolution) compared with those from experimental oxalate solutions. Thus CaP could be a new desensitizing agent in dentin hypersensitivity.
\end{abstract}

Keywords: Dentinal hypersensitivity; Desensitizing agents; Calcium phosphate; Potassium oxalate; Dentin tubule occlusion

\section{Introduction}

Dentinal hypersensitivity $(\mathrm{DH})$ is clinically characterized by transient, sharp pain arising from exposed dentin in response to a stimulus and represents a distinct clinical entity. DH can develop due to the exposure of dentinal tubules, which allows stimuli to create a pressure change or disturbance within the fluid that fills the dentinal tubules and then the fluid movement in the open tubules is transmitted to activate the nociceptor of the odontoblasts.

Dentin tubules exposure could be caused pathologically or iatrogenically. Loss of protective covering over the dentin including the enamel or cementum could be created via physical trauma and/or gingival recession, particularly from overaggressive tooth brushing, chronic periodontitis, and non-surgical periodontal treatments [1,2]. $\mathrm{DH}$ is one of the most commonly encountered clinical problems with a prevalence rate up to $57 \%$ in adults [3]. Noteworthy, a rising incidence of DH in young adults due to increases in consumption of acidogenic diets and tooth whitening products, dental erosion, bruxism and orthodontic procedures, has raised further concerns in dental professionals [4-7].

There are a broad range of products for treatment of DH. The ideal desensitizing agent should be easily applied, rapidly acting, and permanently effective. It should also present an excellent biological tolerance and should not irritate to the dental pulp and soft tissues. Current available approaches attempt to reduce pain by directly changing the action potentials of targeting nociceptive neurons and/or by occluding the exposed dentinal tubules with a precipitating compound. Formulations containing potassium salts such as potassium nitrate, potassium oxalate are widely used as in-office and at-home agents to treat $\mathrm{DH}$. The desensitizing effect of potassium salts presents an immediate effect by neural depolarization from the raising extracellular potassium ions level. In vitro and in vivo studies showed that potassium oxalate demonstrated a great potential for dentin desensitizing [8-13]. Oxalate based dentin desensitizing materials can result in occlusion of open tubules from the precipitation of potassium oxalate. They also react with calcium ions on dentin and in dentinal fluid to form insoluble calcium oxalate crystals. The amount of calcium oxalate precipitate depends on the availability of calcium ions. The oxalate based agent was reported to be relatively short-lived due to the insufficient amount of precipitated crystals which were either partially dissolved in oral fluids or lost during tooth brushing [10,11,13-15].

Effective dentin occlusion should provide the greatest clinical prospect for long-lasting relief of DH. Ideally, the desensitizing material by occluding the tubules should not only be able to coat the exposed dentin surfaces, but also be able to penetrate into the open tubules and form acid resistance plugs to seal these tubules. Such material will offer the intriguing prospect of strengthening dentin and rendering it less susceptible to predisposing factors, while concurrently reducing $\mathrm{DH}$.

Since teeth are mainly constituted by hydroxyapatite, using this primary biologic mineral component of teeth to occlude dentin tubules has aroused great clinical interests [16-19]. A series of clinical and laboratory studies have demonstrated that dentifrices containing hydroxyapatite or Nano-sized hydroxyapatite showed dentin tubules were occluded with crystal precipitate and produced permanent desensitization [16,20-22]. Till now, very little is known about the tubule occlusion and penetration efficacy of hydroxyapatite based materials. Over recent decades, hydroxyapatite-based materials have been modified to enhance mechanical and physiochemical stabilities regarding the restoration of hard tissues such as bone and teeth $[23,24]$. The incorporation of carbonate or fluoride in hydroxyapatite and hydroxyapatite-based minerals has a considerable influence on the 
mechanical and physicochemical properties of the crystals and significantly affects their reactivity and solubility $[24,25]$.

Our preliminary results suggested that dentin surfaces treated with calcium phosphate based solutions containing $\mathrm{Zn}$ and $\mathrm{F}$ ions resulted in dentin tubule occlusion [26] and antibacterial [27]. However, the efficiency of tubule penetration by the $\mathrm{CaP}$ solutions and oxalate solutions agents remains unknown. In this report, we compared the efficacy in occluding dentin tubules between $\mathrm{CaP}$ solutions and oxalate solutions (modified and unmodified) using scanning electron microscopy (SEM) and analysed changes in dentin morphology induced by experimental treatments.

\section{Materials and Methods}

\section{Preparation of the solutions}

Supersaturated mineralizing solution $\mathrm{CaP}$ was prepared from mixtures of calcium deficient apatite (prepared by precipitation), sodium fluoride and zinc chloride (Fisher Scientific, New Jersey). CaP was supersaturated with respect to fluoride and zinc-substituted apatite. OX solution contained $1.6 \mathrm{M} \mathrm{K} \mathrm{K}_{2} \mathrm{C}_{2} \mathrm{O}_{4}$. Modified oxalate solution $\mathrm{OX} / \mathrm{Ca}$ contained $1.6 \mathrm{M} \mathrm{K}_{2} \mathrm{C}_{2} \mathrm{O}_{4}$ and $1.1 \mathrm{M} \mathrm{CaCl}_{2}$. Modified oxalate solution OX/P contained 1.6 $\mathrm{M} \mathrm{K}_{2} \mathrm{C}_{2} \mathrm{O}_{4}$ and $1.7 \mathrm{M} \mathrm{KH}_{2} \mathrm{PO}_{4}$. The oxalate concentration in $\mathrm{OX}, \mathrm{OX} / \mathrm{Ca}$ and $\mathrm{OX} / \mathrm{P}$ is similar to that used in the commercially available oxalate products $\left(30 \% \mathrm{~K}_{2} \mathrm{C}_{2} \mathrm{O}_{4}\right)$ treated for $\mathrm{DH}$. All solutions were adjusted to $\mathrm{pH} 5.5$ at room temperature. The components of the four solutions were shown in Table 1.

\section{Dentin section preparation}

After approved by the Human Research Ethics Committee of Guanghua School of Stomatology, Sun Yat-sen University, human permanent premolars with single-root extracted for orthodontic and surgical reasons were obtained from the Department of Maxillofacial Surgery, Guanghua School of Stomatology, Sun Yat-sen University, immediately stored in saline and sterilized by gamma radiation. Patients with periodontal diseases were not recruited. The crowns were removed using a water-cooled diamond-bladed saw (Series $15 \mathrm{HC}$ Diamond, N 11-4244, Buehler, USA) and the roots were attached to mounting stubs with epoxy resin. Buccal $1 / 2$ or lingual $1 / 2$ dentin pieces were obtained by dividing the roots along the mesio-distal direction and then the coronal $1 / 3$ of dentin sections were selected after removing the root $2 / 3$ from the cut dentin pieces. All dentin sections were then polished on one side using 320 grit, 600 grit, then 1000 grit wet paper and a polishing wheel to create an even and uniform surface. The polished specimens were then cleaned with doubly distilled water (DDW) by ultrasonic cleaner to remove the polishing abrasive material for 3 times and dried with compressed air [26].

\section{Treatment of the dentin sections}

The dentin sections (6 sections per group) were randomly distributed into treated groups (Groups $\mathrm{CaP}, \mathrm{OX} / \mathrm{Ca}, \mathrm{OX} / \mathrm{P}$, and $\mathrm{OX}$ ) and control group reflecting the treatment solutions used. The sections were immersed in solutions $\mathrm{CaP}, \mathrm{OX} / \mathrm{Ca}, \mathrm{OX} / \mathrm{P}$ and $\mathrm{OX}$ respectively with shaking speed of $60 \times \mathrm{rpm}$ for 8 minutes (the immersion was renovated with fresh solution every 2 minutes), rinsed in DDW, dried with compressed air and stored in a desiccator until required for analysis. The control group underwent the same procedure except the sections were treated with DDW.

\section{Characterization of dentin surface morphology}

The treated and control dentin sections were mounted on aluminium stubs with graphite adhesive and sputter coated with gold and characterized using scanning electron microscopy (SEM, JEOL JSM-5400; JEOL USA, Inc., Peabody, MA; and Hitachi S-3500N; Hitachi, Ltd., Tokyo, Japan). Images were taken from selected fields in the central portion of each section at varying magnifications $(\mathrm{X} 1 \mathrm{~K}$, $\mathrm{X} 3 \mathrm{~K}$, and $\mathrm{X} 5 \mathrm{~K})$. Deposited particle size was measured under SEM (X10K).

\section{Determination of percentage of occluded and dissolved dentin tubules (DT) before and after acid treatment}

Using SEM images of X1K magnification, the ratio of the number of occluded dentin tubules (ODT) to the total number of dentin tubules (TDT) in random areas per section was determined. Per cent (\%) of occlusion was calculated as $($ ODT/TDT $) \times 100$. Six equivalent areas for each of three dentin sections in each group were measured and calculated as mean $\pm \mathrm{SD}$.

After the calculation, three dentin sections per group were immersed in 5\% sodium cyanide for 10 minutes to dissolve the gold coating, rinsed with DDW and dried with compressed air. Further, all dentin sections surfaces were applied with nail varnish except a $5 \mathrm{~mm}$ diameter circular area and immersed in $25 \mathrm{ml}$ acidic buffer $(0.1 \mathrm{M} \mathrm{KAc}$, $\mathrm{pH} 6.0,37^{\circ} \mathrm{C}$ ) for 60 minutes on the shaker with the speed of $60 / \mathrm{min}$. All specimens were further rinsed with DDW and then dried with compressed air. The treated and control dentin sections were mounted on aluminium stubs and sputter coated with gold and characterized using SEM. Percent (\%) of occlusion after immersed in KAc was calculated as before. After exposure to the acidic buffer, changes in surface morphology and in the per cent of occluded dentin tubules were determined using SEM.

\section{Analysis of SEM images}

The dentin sections were analysed and compared among different dentinal desensitizing solutions prepared in this study using SEM. The images were processed using ImageJ (version 1.47; National Institutes of Health). For analysis, random regions of interest (ROI) [28] were selected and converted to binary images.

Distribution patterns and cross-sectional areas of dentinal tubules were analysed in nine random ROI from three samples in each group using the Surface Plot analysis tool (ImageJ version 1.47; National Institutes of Health) which displayed an intensity plot for foreground pixels of the ROI. Bars reflected the location and area of tubules in the ROI.

\section{Characterization of fractured dentin surface morphology}

Three dentin sections per group were fractured to reveal crystals within the dentin tubules and examined by SEM (X1K and X5K). Six equivalent areas from SEM images of the X1K magnification for each of three dentin sections were measured and the mean \pm SD of the depths of precipitates occluded into dentin tubules in each group were calculated.

\section{Statistical analysis}

SPSS statistical software (SPSS v.16; Chicago, Illinois, US) was used for the statistical analysis of data. All results were presented as the 
mean \pm SD of the measurements. Differences in the tubule penetrating depth and percentage of occlusion in different groups were analysed by one-way analysis of variance (ANOVA) followed by Student-NewmanKeuls or Dunnett's T3 post hoc test at the significance level of 0.05 .

\section{Results}

\section{CaP solution precipitated more crystals with small particle size on dentin surfaces}

As shown in Figure 1, crystal precipitates were observed on the treated dentin surfaces but not on the control surfaces under SEM. Surfaces treated with solution $\mathrm{CaP}$ showed greater amount of crystals than those with solutions $\mathrm{OX} / \mathrm{Ca}, \mathrm{OX} / \mathrm{P}$ and $\mathrm{OX}$. In the $\mathrm{CaP}$ group, there were fine crystals covering the dentin surface with a homogeneous precipitates layer which made most of the tubule openings invisible.

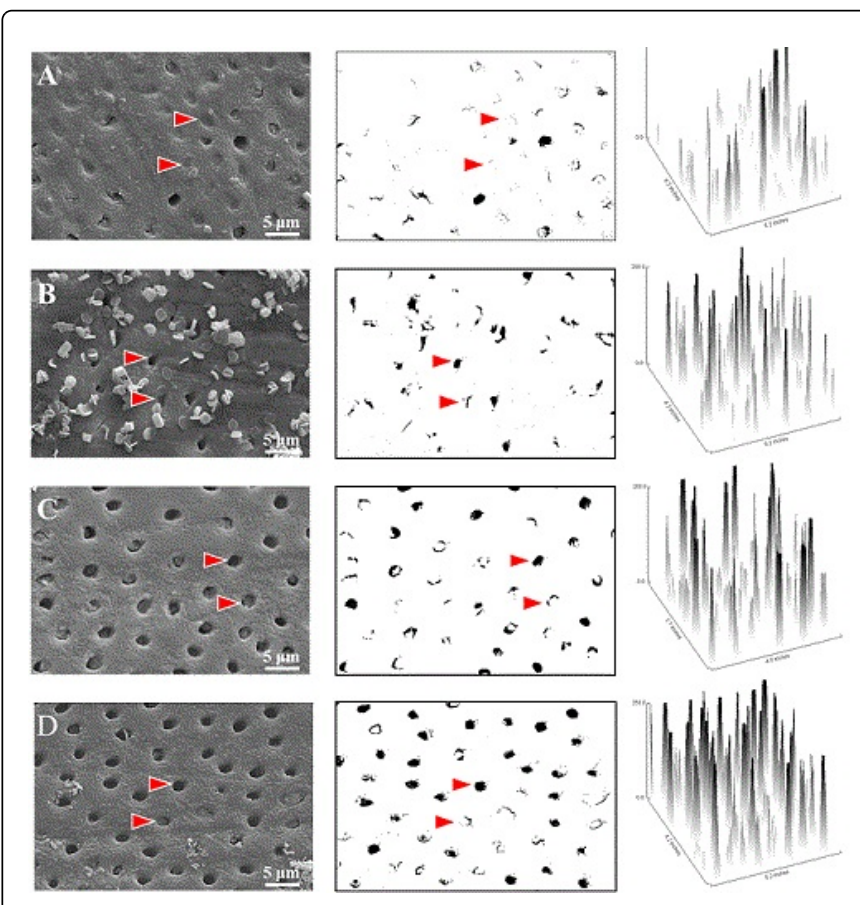

Figure 1: Comparison of cross-sectional dentin surfaces treated by different solutions. Representative SEM images (left panel) were selected and analysed after binary conversion (middle panel) using ImageJ. Surface plots (right panel) were generated to confirm the observation. (A) CaP solution treated, most of the dentin tubules were occluded with an apparently smooth layer (arrow); (B) OX/Ca solution treated, different shapes of large crystals were seen on the dentin surfaces and a few of the tubule openings remained visible (arrow); (C) OX/P solution treated, this solution provided a covering on the dentin surface with deposited crystals, some tubules were occluded and some tubule openings remained visible (arrow); (D) OX solution treated, small particles were found at the dentin surface with little effect on tubule occlusion, and most of openings remained visible (arrow); (E) control dentin, open dentin tubules are indicated by arrows. A, B, C, D and $\mathrm{E}$ (magnification $\mathrm{X} 3 \mathrm{~K}$ ).

The precipitated micro-crystals were better presented under higher magnification shown in Figure 2. Similar crystal precipitates were also observed in dentin sections treated with solution OX/P. In contrast, large bulky crystal precipitates were found in OX/Ca treated group. Moreover, the formed crystals in OX/Ca group tended to cluster together. However, some tubule openings remained visible in groups treated with OX/Ca or OX/P solution. Most of the dentin tubules could be seen from OX solution treated group. It appeared to be the least effective on the surface coverage and tubule occlusion. Scanty crystal particles were observed at the surface and there was no obvious intratubular occlusion presented.

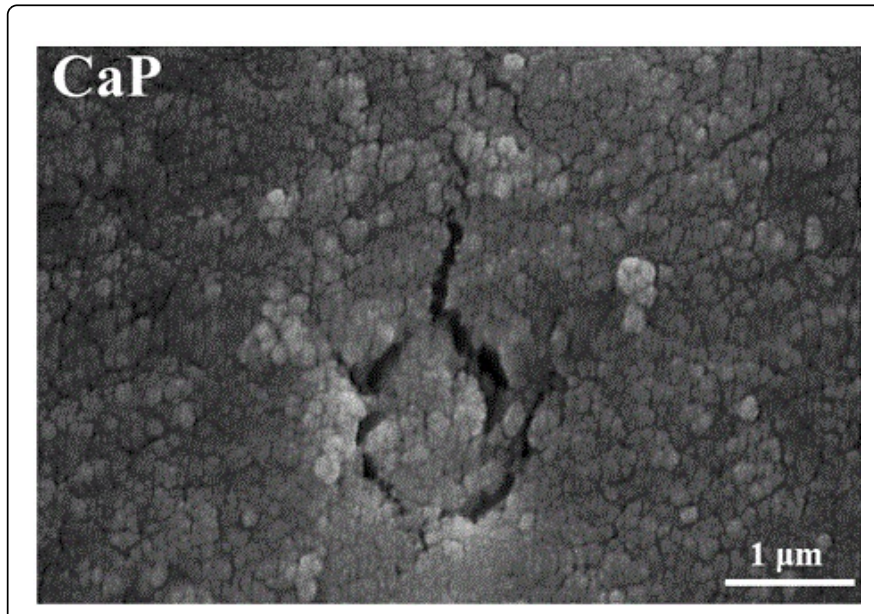

Figure 2: SEM images of $\mathrm{CaP}$ solution treated dentin tubule at $\times 20 \mathrm{~K}$ magnification; the tubule was totally occluded with micro-crystals.

Under SEM, the deposited particle size (mean \pm SD) in each group was (in Nanometres): $287 \pm 31,1848 \pm 115,354 \pm 53$ and $439 \pm 50$ for apatite crystals from surfaces treated with solutions $\mathrm{CaP}, \mathrm{OX} / \mathrm{Ca}, \mathrm{OX} / \mathrm{P}$, and OX respectively.

\section{CaP plugs penetrated deepest into dentin tubules than oxalate-based solutions}

In longitudinal fractured sections, long crystal plugs occluded most tubules on dentin sections treated with solution $\mathrm{CaP}$ (Figure $3 \mathrm{~A}$ ). In OX/Ca treated group, most of the crystals only deposited at the dentin tubule openings on the surface instead of penetrating into tubules (Figure 3B). Short coarse crystal plugs were also noticed in the OX/P treated dentin sections in which dentin tubules were penetrated with crystals (Figure 3C). However, OX solution had little effect on tubule occlusion, only scattered tiny crystal-like precipitates were observed within the dentin tubules at some distance below the surface (Figure $3 \mathrm{D})$. The mean penetration depth (mean $\pm \mathrm{SD}$ ) of crystal precipitates formed in dentin tubules were measured: $\mathrm{CaP}$ at $9.42 \pm 1.56 \mu \mathrm{m}$, $\mathrm{OX} / \mathrm{Ca}$ at $0.87 \pm 0.27 \mu \mathrm{m}, \mathrm{OX} / \mathrm{P}$ at $4.15 \pm 0.93 \mu \mathrm{m}$, and $\mathrm{OX}$ at $1.21 \pm$ 0.79 respectively (Figure $3 \mathrm{E}$ and Figure $3 \mathrm{~F}$ ). There was a significant difference $(p<0.01)$ between $\mathrm{CaP}$ group and the other groups. Worthwhile to note, the difference between OX/P treated group and $\mathrm{OX} / \mathrm{Ca}$ or OX group was statistically significant as well $(\mathrm{p}<0.01)$. There was no significant difference between groups OX/Ca and OX $(\mathrm{p}>0.01)$.

\section{Precipitates and plugs formed in CaP solution presented better acid-resistance compared with oxalate-based solutions}

Morphology changes on dentin surfaces were observed after exposure to acidic buffer for 1 hour (Figure 4). Reasonable amount of 
crystal precipitates still remained on the dentinal surfaces and inside the tubules treated with solution CaP.
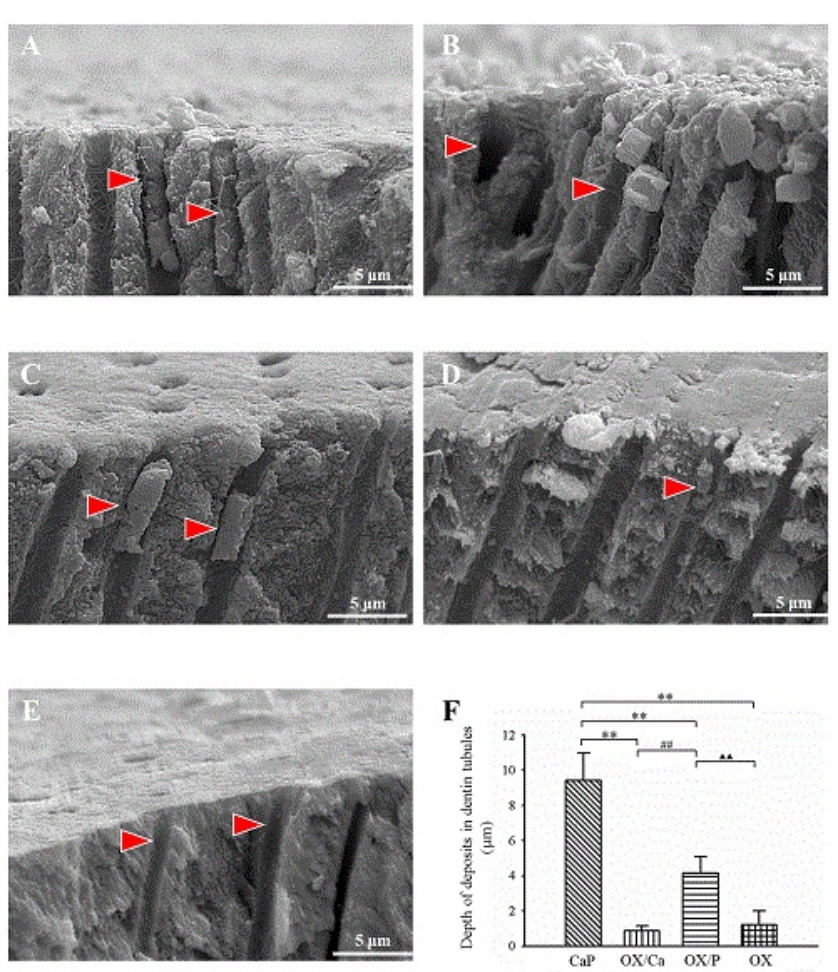

Figure 3: SEM images of fractured dentin sections. (A) CaP solution treated, longitudinal plugs (arrow) penetrated below the dentin surface; (B) OX/Ca solution treated, no crystals were observed at the deep part of dentin tubules, only a small amounts of big size crystals were observed in the opening of dentin tubules (arrow); (C) $\mathrm{OX} / \mathrm{P}$ solution treated, dentin tubules were penetrated with crystals (arrow); (D) OX solution treated, crystals-like particles were observed within some tubules (arrow); (E) control dentin, open dentin tubules are indicated by arrows. (Magnification X5K). (F) The mean depth of the precipitate formed in the dentin tubules by solutions $\mathrm{CaP}, \mathrm{OX} / \mathrm{Ca}$, OX/P and OX. Crystals formed by $\mathrm{CaP}$ solution were observed to be significantly occluded into dentin tubules compared with solutions OX/Ca, OX/P and OX $\left({ }^{*} \mathrm{p}<0.01\right)$. Compared with solution $\mathrm{OX} / \mathrm{Ca}$, crystals formed by OX/P 21 solution were significantly occluded into dentin tubules $\left({ }^{\#} \mathrm{p}<0.01\right)$. Compared with solution OX, crystals formed by OX/P solution were significantly occluded into dentin tubules $(\mathrm{p}<0.01)$. All values were depicted as mean $\pm \operatorname{SD}(n=6)$.

While the majority of the deposits on the dentin surfaces treated with other solutions were noticed to be dissolved after acidic exposure. As shown in surface plots of Figure 4, except CaP treated group, the tubules from other treatments were re-opened up with wide tubule openings, which were similar with that in the control group.

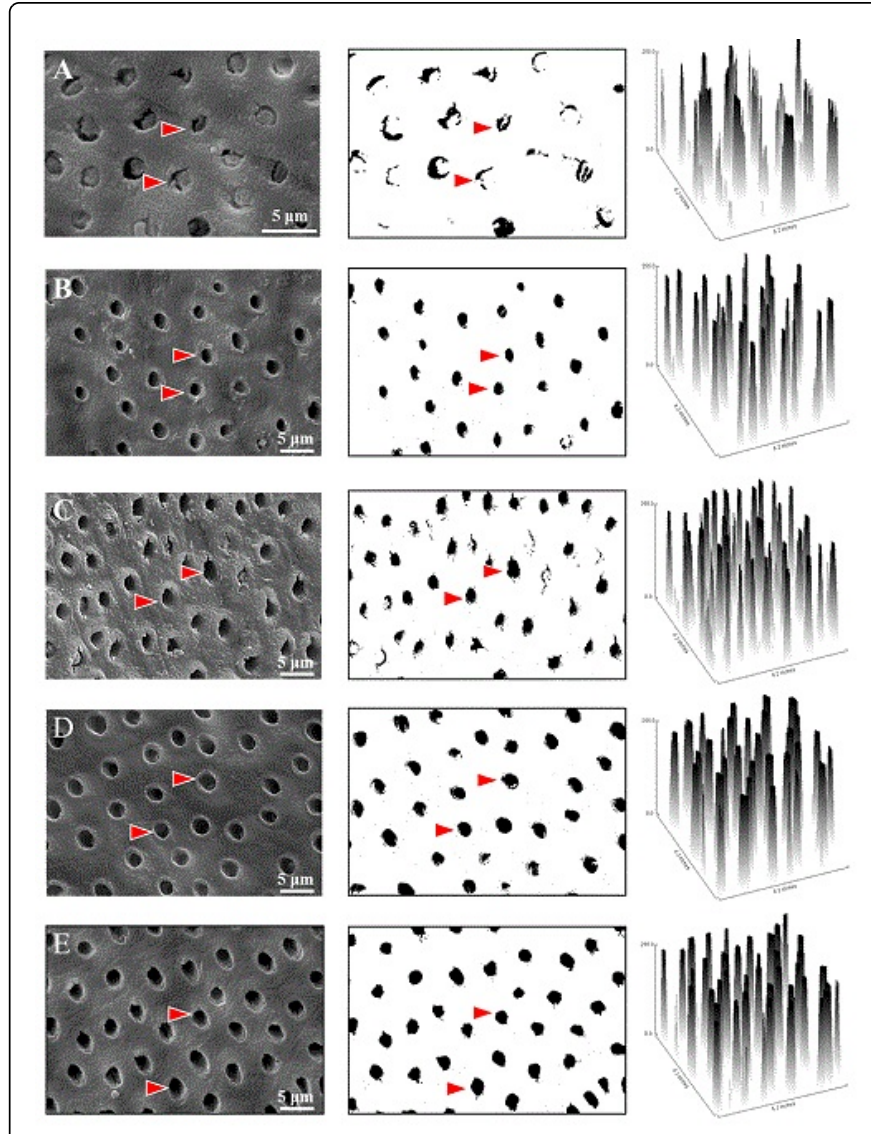

Figure 4: SEM images of treated dentin surfaces after exposed to acidic buffer for 60 minutes. Representative SEM images (left panel) were selected and analysed after binary conversion (middle panel) using ImageJ. Surface plots (right panel) were generated to confirm the observation. (A) CaP solution treated, most of deposits in the dentin tubules still remained (arrow) (magnification X3K); (B, C, and D) OX/Ca, OX/P and OX solution treated, most of deposits on the dentin surface or inside the dentin tubules had been dissolved; (E) control dentin. A (magnification X20K); B, C, D, and E (magnification $\mathrm{X} 3 \mathrm{~K}$ ). Open dentin tubules are indicated by arrows.

Proportion of occluded dentin tubules was $82 \%$ for surfaces treated with solution $\mathrm{CaP}, 52 \%$ for $\mathrm{OX} / \mathrm{Ca}, 53 \%$ for $\mathrm{OX} / \mathrm{P}$, and $21 \%$ for OX. After dentin sections were immersed in $25 \mathrm{ml}$ acidic buffer $(0.1 \mathrm{M} \mathrm{KAc}$, $\mathrm{pH} 6.0,37^{\circ} \mathrm{C}$ ) for 60 minutes, accordingly, the per cents of remaining occluded dentin tubules were $61 \%, 9 \%, 14 \%$, and $5 \%$ respectively. The percentage of occluded dentin tubules treated with $\mathrm{CaP}, \mathrm{OX} / \mathrm{Ca}, \mathrm{OX} / \mathrm{P}$ and OX solutions were significantly decreased $(\mathrm{p}<0.01)$ after 60 minute acidic challenge (shown in Figure 5A). Compared with $\mathrm{CaP}$ group, percentage of dissolved dentin tubules were significantly higher in $\mathrm{OX} / \mathrm{Ca}, \mathrm{OX} / \mathrm{P}$, or OX group $(\mathrm{p}<0.01)$. However, there were no significant differences between groups $\mathrm{OX} / \mathrm{Ca}$ and $\mathrm{OX} / \mathrm{P}, \mathrm{OX} / \mathrm{Ca}$ and OX, OX/P and OX ( $>0.01)$ (shown in Figure 5B). 


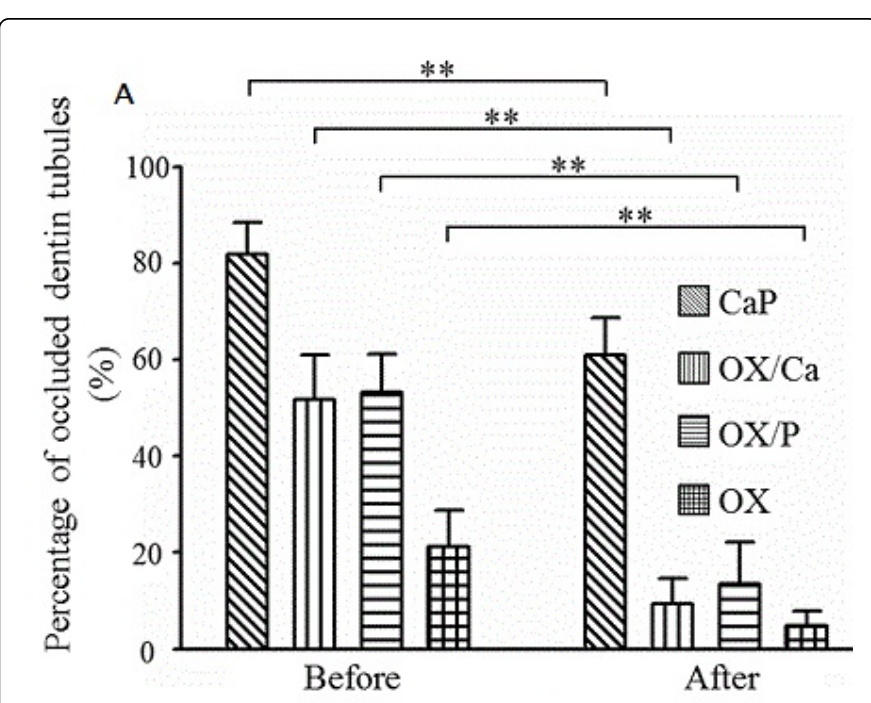

Acid treatment

B

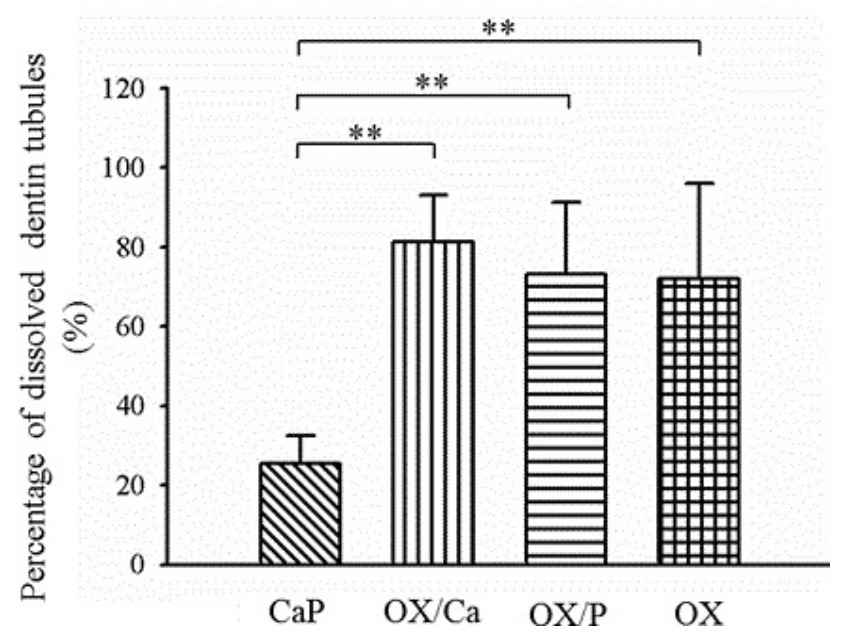

Figure 5: (A) Percentage of occluded dentin tubules and (B) percentage of dissolved dentin tubules. After 60-minute exposure to the acid buffer, the occluded dentin tubules treated with Cap, $\mathrm{OX} / \mathrm{Ca}, \mathrm{OX} / \mathrm{P}$ and $\mathrm{OX}$ solutions decreased significantly $\left({ }^{*} \mathrm{p}<0.01\right)$. Compared with $\mathrm{CaP}$ group, deposits in dentin tubules formed in Group OX/Ca, OX/P and OX were significantly dissolved after exposed to acidic buffer for 60 minutes $\left({ }^{*} \mathrm{p}<0.01\right)$. All values were depicted as mean $\pm \operatorname{SD}(n=6)$.

\section{Discussion}

The solutions used in this study included:

- Calcium phosphates based solution $\mathrm{CaP}$ supersaturated with respect to fluoride and zinc-substituted apatite;

- Oxalate modified solution $\mathrm{OX} / \mathrm{Ca}$ - supplemented with $\mathrm{CaCl}_{2}$ in potassium oxalate solution;
- OX/P solution - supplemented with $\mathrm{NaH}_{2} \mathrm{PO}_{4}$ in potassium oxalate solution;

- OX solution - prepared by dissolved $\mathrm{K}_{2} \mathrm{C}_{2} \mathrm{O}_{4}$ in DDW.

Changes in precipitates coated surfaces and subsurface morphology were demonstrated in the SEM images. The difference in per cent of occluding the dentin tubules was also compared before and after acetic acid treatment.

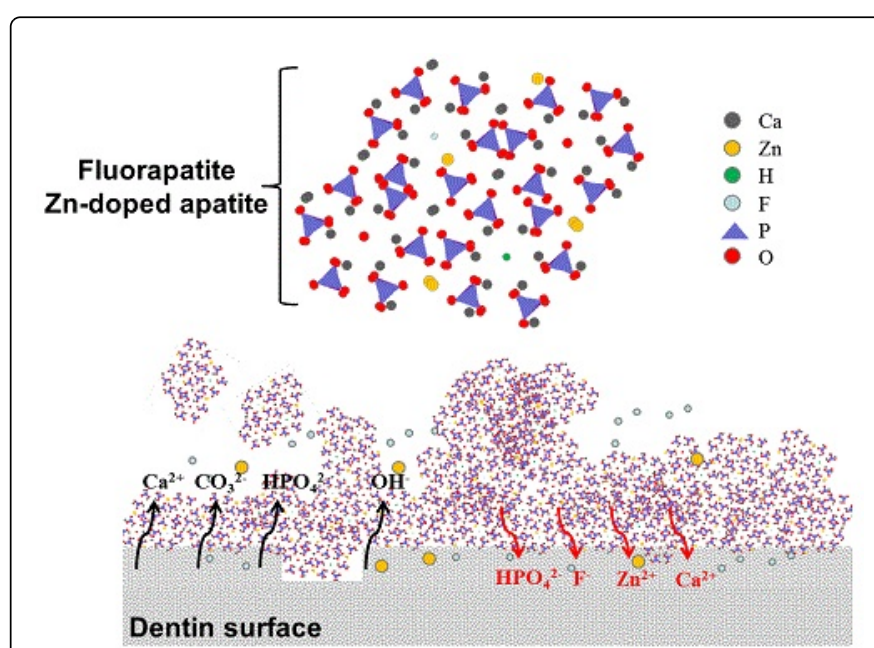

Figure 6: Schematic diagram of the proposed mechanism of modified $\mathrm{CaP}$ solution precipitated on the exposed dentin surface.

In this study, our modified CaP solution presented a prominent effectiveness and performance regarding the occlusion of open tubules. The CaP solution also sealed the dentinal surface with continuous, homogenous precipitates. Compared with oxalate solutions only, oxalate supplemented with either calcium or phosphate ions were more effective in occluding the dentine tubules. The higher occlusion percentage observed in OX/Ca solution treatment was attributed to high level of calcium ions in the OX/Ca which promoted the formation of abundant calcium oxalate crystals. Although potassium oxalate has been reported potential effectiveness in occluding dentin tubules and reducing dentinal permeability $[13,14]$, the OX solution $(30 \%$ potassium oxalate) used in this study only formed limited oxalate crystals on the dentinal surfaces. The low rate of calcium oxalate crystal production from this solution may be limited by the low level of ionized calcium released from the dentin mineral, or the dissolution of formed calcium oxalate under the low $\mathrm{pH}$ environment ( $\mathrm{pH}$ 5.5). Our observation supports a previous study by Suge $\mathrm{T}$ et al, in which different potassium oxalate solutions failed in occluding wide-open dentin tubules [29].

A better surface occlusion is necessary for dentin desensitizing agents to protect the exposed tubules and generate sound clinical outcomes. However, the formed precipitates on the dentin surface are still susceptible to subsequent abrasion from daily home care for oral hygiene. Hence, the depth of crystal precipitates penetrated into the dentinal tubules, to some extent, plays a more critical role to achieve a better desensitizing effect and long-term lasting outcome. Our study demonstrated that the crystals formed in $\mathrm{CaP}$ group penetrated deeply into the tubules $9.4 \mu \mathrm{m}$ from surface. More importantly, the precipitated crystals from $\mathrm{CaP}$ solution also formed larger compact plugs to obliterate the open tubules. To further investigate the mechanism of plugs formation, we also examined the size of 
precipitated particles using SEM under high magnification. We found that the particle size (mean $\pm \mathrm{SD}$ ) of the apatite crystals in CaP group was $287 \pm 31 \mathrm{~nm}$, which allowed the precipitates to penetrate successfully into the open dentinal tubules (the average cervical diameters ranged from 1.65 to $1.80 \mu \mathrm{m}$ ) [26]. Meanwhile, the deposited $\mathrm{CaP}$ crystals inside the tubules promoted further nucleation to form larger plugs which blocked the open tubules in deeper zones (shown in Figure 3).

Compared with CaP solution, the modified and unmodified oxalate solutions were much less effective to produce occlusion plugs in the dentin tubules. As shown in our fractured dentin surface, OX/Ca precipitates covered the opening of exposed tubules, but they failed to occlude and enter the exposed tubules. This may be contributed to the larger particle size $(1.85 \pm 0.12 \mu \mathrm{m})$ of calcium oxalate crystals. Noteworthy, phosphate supplemented oxalate solution OX/P presented an improved performance than OX and OX/Ca solutions. It is noticed that $\mathrm{OX} / \mathrm{P}$ solution could deposit deeply into the tubules and more tubules were obliterated by the plugs. With the reaction between the additional phosphate ions and $\mathrm{Ca}_{2}{ }^{+}$ions released from the dissolved dentin mineral, calcium phosphate apatite precipitates with smaller size relative to calcium oxalate were formed, which indicates the potential application of OX/P solution in occluding the narrower or partially closed dentin tubules. It is noteworthy that many minerals, such as calcium carbonate, can be dissolved in acids, while they have a very low solubility in pure water. Also, the $\mathrm{pH}$ value in oral cavity is normally 6.5-7.5 and after eating and drinking, it drops to dangerously low levels because of plaque acids produced by bacterial plaque, which increases the risks of tooth sensitivity and tooth decay.

Thus, in order to achieve a long-lasting relief of sensitivity, the ideal dentin desensitizing agent should be able to form an occlusion with acid resistance against a potential acidogenic challenge in oral environment. Compared with the oxalate precipitates, the $\mathrm{CaP}$ precipitates showed a better acid resistance in this study. The majority of formed precipitates sealed the tubules still survived after a stringent acid attack. As revealed in our previous study, the $\mathrm{CaP}$ mineralizing solution mainly contains a more acid resistant form of precipitate, calcium hydroxyapatite, other than the simple calcium phosphate crystals [26]. It is known that the calcium hydroxyapatite $\left(\mathrm{Ca}_{10}\left(\mathrm{PO}_{4}\right)_{6}(\mathrm{OH})_{2}\right)$ structure allows the substitution of their calcium, phosphate and hydroxyl groups by other ions in acidic conditions [24]. Under pH 5.5 condition implemented in this study, the formation of fluorapatite and $\mathrm{Zn}$-doped apatite was achieved by the F- substitution for $\mathrm{OH}$ - and $\mathrm{Zn}^{2+}$ substitution for $\mathrm{Ca}^{2+}$ respectively (Figure 6). Dentin comprises by $50 \%(\mathrm{vol} / \mathrm{vol})$ of a calcium-deficient carbonate hydroxyapatite. With this in mind, supplemented with fluoride in the $\mathrm{CaP}$ solution promotes the formation of fluorapatite which is most effective in inhibiting the dissolution of dentinal hydroxyapatite [30]. In contrast, oxalate precipitates were dissolved after 1 hour acid exposure. Calcium oxalate crystals are reported to liberate ionized calcium once exposed to $\mathrm{H}_{3} \mathrm{O}^{+}$[30]. With regard to acid resistance, supplemented with additional calcium in oxalate based solutions was shown to be improved, but to a minimum extent.

Hence, our modified $\mathrm{CaP}$ solution created an acid-and wearresistant shield for the tooth in comparison with oxalate based materials. To maintain this stable plugging and sealing precipitates, the integration of the $\mathrm{CaP}$ and the dentin surface is proposed to be not only mechanical bonding but also chemical bonding in nature. As shown in Figure 6, under weak acidic condition ( $\mathrm{pH} 5.5)$, the dentin mineral, particularly carbonate apatite, was partially dissolved on the binding surface and liberated $\mathrm{Ca}^{2+}, \mathrm{Mg}^{2+}, \mathrm{HPO}_{4}{ }^{2-}, \mathrm{CO}_{3}{ }^{2-}$ ions. Meanwhile, the $\mathrm{Ca}^{2+}, \mathrm{Zn}^{2+}, \mathrm{F}^{-}, \mathrm{HPO}_{4}^{2-}$ ions from the $\mathrm{CaP}$ solution would migrate into the vacancies created by ions loss in dentinal HA lattice, and then incorporate into an precipitated apatitic layer that had lower $\mathrm{CO}_{3}{ }^{2-}$ ion concentration and higher $\mathrm{F}$ - ion concentration, which ultimately attributed to lower solubility and better acid resistance. Furthermore, this ion exchange process in combined with mechanical boding would provide the $\mathrm{CaP}$ precipitates more resistant to physical abrasión [30,32-35]. In addition, $\mathrm{CaP}$ solution possessed antibacterial activity since $\mathrm{F}-$ and $\mathrm{Zn}^{2+}$ ions can reduce the metabolism rate of oral bacteria [36], inhibit bacterial growth and colonization [37]. Coinciding with the report that the combination of zinc plus fluoride presented strong bactericidal effects [38], our previous study also demonstrated that $\mathrm{CaP}$ was effective to inhibit the colonization and growth of cariogenic pathogen Streptococcus Mutans [27].

In conclusion, the efficiency of the four dentin desensitizing solutions in occluding and plugging dentin tubules could depend on several factors, such as composition of the desensitizing solutions, dentinal apatite crystal properties, the crystalline size and the number of crystals as discussed in this study. Oxalate solutions do not modify the surface properties of dentin, in terms of composition and dentin apatite crystal properties, whilst $\mathrm{CaP}$ solutions and oxalate-based solutions showed that the dentin surfaces were covered and the dentin tubules were occluded to varied degrees. Compared with OX/Ca, OX/P and $\mathrm{OX}, \mathrm{CaP}$ solution was the most effective in occluding the dentin tubules before and after acid exposure and penetrating crystals into the deeper parts of the tubules in fractured specimens. Overall, the physical and chemical properties of $\mathrm{CaP}$ could provide a great potential to reduce dentinal hypersensitivity clinically. Further in vitro and in vivo studies are required to determine the effects of these agents on dentin permeability (fluid flow), stability on abrasion, durability and the effectiveness in reducing pain over time (Table 1).

\begin{tabular}{|l|l|l|}
\hline Solutions & pH & Components \\
\hline CaP & 5.5 & Fluoride and zinc-substituted apatite \\
\hline OX & 5.5 & $30 \%(w / v)$ potassium oxalate \\
\hline OX/Ca & 5.5 & $30 \%(w / v)$ potassium oxalate with $\mathrm{Ca2}^{+}$ions \\
\hline OX/P & 5.5 & $30 \%(w / v)$ potassium oxalate with HPO42- ions \\
\hline DDW & 7.0 & Double distilled water \\
\hline
\end{tabular}

Table 1: Compositions and $\mathrm{pHs}$ of the solutions used to treat dentin surfaces. 


\section{Acknowledgments}

We gratefully acknowledge the professional collaboration of Drs. W. Zou, Y. Liu, X. Sun, H. Bin and D. Holmes and K Lewis. This investigation was supported by the National Natural Science Foundation of China (No.81200777) and the Fundamental Research Funds for the Central Universities (No.12ykpy66)

\section{Competing Interests}

The authors have declared that no competing interests exist.

\section{References}

1. Addy M, Pearce N (1994) Aetiological, predisposing and environmental factors in dentine hypersensitivity. Arch Oral Biol Suppl: 33S-38S.

2. Xu BD, Yang PS (2004) The effects of non-surgical periodontal treatment on the formation of root-dentin hypersensitivity. Shanghai Kou Qiang Yi Xue 13: 238-240.

3. Cummins D (2009) Dentin hypersensitivity: from diagnosis to a breakthrough therapy for everyday sensitivity relief. J Clin Dent 20: 1-9.

4. Pohjola RM, Browning WD, Hackman ST, Myers ML, Downey MC (2002) Sensitivity and tooth whitening agents. J Esthet Restor Dent 14: 85-91.

5. Browning WD, Chan DC, Myers ML, Brackett WW, Brackett MG (2008) Comparison of traditional and low sensitivity whiteners. Oper Dent 33: 379- 385 .

6. Jacobsen PL, Bruce G (2001) Clinical dentin hypersensitivity understanding the causes and prescribing a treatment. J Contemp Dent Pract 2: 1-12.

7. Sykes LM (2007) Dentine hypersensitivity. a review of its aetiology, pathogenesis and management. SADJ 62: 066-071.

8. Ling TY, Gillam DG, Barber PM, Mordan NJ, Critchell J (1997) An investigation of potential desensitizing agents in the dentine disc model: a scanning electron microscopy study. J Oral Rehabil 24: 191-203.

9. Sauro S, Gandolfi MG, Prati C, Mongiorgi R (2006) Oxalate-containing phytocomplexes as dentine desensitisers: An in vitro study. Archives of Oral Biology 51: 655-664

10. Gillam DG, Mordan NJ, Sinodinou AD, Tang JY, Knowles JC (2001) The effects of oxalate-containing products on the exposed dentine surface: an SEM investigation. J Oral Rehabil 28: 1037-1044.

11. Kerns DG, Scheidt MJ, Pashley DH, Horner JA, Strong SL (1991) Dentinal tubule occlusion and root hypersensitivity. J Periodontol 62: 421 428.

12. Muzzin KB, Johnson R (1989) Effects of Potassium Oxalate on Dentin Hypersensitivity Invivo. J Periodontol 6: 151-158.

13. Pashley DH, Galloway SE (1985) The effects of oxalate treatment on the smear layer of ground surfaces of human dentine. Arch Oral Biol 30: 731-737.

14. Pereira JC, Segala AD, Gillam DG (2005) Effect of desensitizing agents on the hydraulic conductance of human dentin subjected to different surface pretreatments--an in vitro study. Dent Mater 21: 129-138.

15. Camps J, Pashley D (2003) In vivo sensitivity of human root dentin to air blast and scratching. J Periodontol 74: 1589-1594.

16. Shetty S, Kohad R, Yeltiwar R (2010) Hydroxyapatite as an In-Office Agent for Tooth Hypersensitivity: A Clinical and Scanning Electron Microscopic Study. J Periodontol 81: 1781-1789.

17. Suge T, Ishikawa K, Kawasaki A, Yoshiyama M, Asaoka K (1995) Duration of dentinal tubule occlusion formed by calcium phosphate precipitation method: In vitro evaluation using synthetic saliva. J Dent Res 74: 1709-1714.
18. Earl JS, Wood DJ, Mine SJ (2006) Hydrothermal synthesis of hydroxyapatite. J physics 26: 268-271.

19. Kim SH, Park JB, Lee CW, Koo KT, Seol YJ (2009) The clinical effects of a hydroxyapatite containing toothpaste for dentin hypersensitivity. J Korean Acad Periodontol 39: 87-94.

20. Tam L (2012) Commentary. Effect of a nano-hydroxyapatite paste on bleaching-related tooth sensitivity. J Esthet Restor Dent 24: 277.

21. Browning WD, Cho SD, Deschepper EJ (2012) Effect of a nanohydroxyapatite paste on 17 bleaching-related tooth sensitivity. J Esthet Restor Dent 24: 268-276.

22. Takikawa RK, Ishizaki T, Hayman R (2004) Restoration of post-bleach enamel gloss using a non-abrasive, nano-hydroxyapatite conditioner. Journal of Dental Research 85(Special Issue B).

23. Glimcher MJ, Glimcher MJ (2006) Bone: nature of the calcium phosphate crystals and cellular, structural, and physical chemical mechanisms in their formation. In: Sahai N, Schoonen MAA, editors. Medical mineralogy and geochemistry. Reviews in mineralogy and geochemistry, vol. 64. Washington, DC: Mineralogical Society of America 223-282.

24. Elliott JC (2002) Calcium phosphate biominerals. In: Kohn MJ, Rakovan J, Hughes JM, editors. Phosphates: geochemical, geobiological, and materials importance. Reviews in mineralogy and geochemistry, vol. 48 . Washington, DC: Mineralogical Society of America 427-453.

25. Yao F, LeGeros JP, LeGeros RZ (2009) Simultaneous incorporation of carbonate and fluoride in synthetic apatites: Effect on crystallographic and physico-chemical properties. Acta Biomater 5: 2169-2177.

26. Gu H, Ling J, LeGeros JP, LeGeros RZ (2011) Calcium phosphate-based solutions promote dentin tubule occlusions less susceptible to acid dissolution. Am J Dent 24: 169-175.

27. Gu H, Mijares D, Zhao Z, Boylan R, Ling J (2013) Experimental antibacterial and mineralizing calcium phosphate-based treatment for dentin surfaces. J Biomater Appl 27:783-790.

28. Geoffroy V, Marty-Morieux C, Goupil N, Clement-Lacroix P, Terraz C (2004) In vivo inhibition of osteoblastic metalloproteinases leads to increased trabecular bone mass. J Bone Miner Res 19: 811-822.

29. Suge T, Kawasaki A, Ishikawa K, Matsuo T, Ebisu S (2005) Comparison of the occluding ability of dentinal tubules with different morphology between calcium phosphate precipitation method and potassium oxalate treatment. Dent Mater J 24: 522- 529.

30. LeGeros RZ (1991) Calcium phosphates in oral biology and medicine. Monogr Oral Sci 15:1-201.

31. Silberberg MS (2003) Equilibrium: the extent of chemical reactions. In: Chemistry. The molecular nature of matter and change. 3rd ed. New York: McGraw-Hill, pp: 736-739.

32. LeGeros RZ (1990) Chemical and crystallographic events in the caries process. J Dent Res 69 Spec No: 567-574.

33. Matsunaga K, Murata H, Mizoguchi T, Nakahira A (2010) Mechanism of incorporation of zinc into hydroxyapatite. Acta Biomater 6: 2289-2293.

34. Miyaji F, Kono Y, Suyama Y (2005) Formation and structure of zincsubstituted calcium hydroxyapatite. Mater Res Bull 40: 209-220.

35. Bigi A, Foresti E, Gandolfi M, Gazzano M, Roveri N (1995) Inhibiting effect of zinc on hydroxylapatite crystallizaion. J Inorg Biochem 58: 49-58.

36. Van Loveren C, Fielmich AM, Ten Brink B (1987) Comparison of the effects of fluoride and the ionophore nigericin on acid production by Streptococcus mutans and the resultant in vitro enamel demineralization. J Dent Res 66: 1658-1662.

37. Chou AH, LeGeros RZ, Chen Z, Li Y (2007) Antibacterial effect of zinc phosphate mineralized guided bone regeneration membranes. Implant Dent 16: 89-100.

38. Izaguirre-Fernandez EJ, Eisenberg AD, Curzon ME (1989) Interactions of zinc with fluoride on growth, glycolysis and survival of Streptococcus mutans GS-5. Caries Res 23: 18-25. 